\title{
Harmonisation of respiratory medicine: the success story of European curriculum development
}

\author{
Daiana Stolz ${ }^{1}$, Nathalie Tabin', Amy Farr ${ }^{2}$ \\ ${ }^{1}$ Clinic of Respiratory Medicine and Pulmonary Cell Research, University Hospital Basel, Basel, Switzerland; ${ }^{2}$ Education Department, European \\ Respiratory Society, Lausanne, Switzerland \\ Contributions: (I) Conception and design: D Stolz; (II) Administrative support: N Tabin, A Farr; (III) Provision of study materials or patients: All \\ authors; (IV) Collection and assembly of data: All authors; (V) Data analysis and interpretation: All authors; (VI) Manuscript writing: All authors; (VII) \\ Final approval of manuscript: All authors. \\ Correspondence to: Nathalie Tabin. Education Department, European Respiratory Society, Av. Ste-Luce 4, 1003 Lausanne, Switzerland. \\ Email: Nathalie.tabin@ersnet.org.
}

\begin{abstract}
In 2005, the European Respiratory Society (ERS) launched a project to harmonise education and training and to address the heterogeneity of respiratory health training across Europe. Since then, various educational activities have been developed for different target audiences. This article will describe the overall methodology and the projects developed over the years, detailing their objectives and target audiences. Moving forward, ERS strives to provide a structure for the continuing professional development of respiratory physicians.
\end{abstract}

Keywords: Education; curriculum design; syllabus; respiratory medicine; continuing professional development

Submitted Nov 13, 2018. Accepted for publication Feb 14, 2019.

doi: $10.21037 /$ jtd.2019.02.40

View this article at: http://dx.doi.org/10.21037/jtd.2019.02.40

\section{Introduction}

Respiratory medicine is one of the largest medical specialties, covering a wide range of acute and chronic diseases. It is expected that one in eight people in Europe will die due to lung disease, which equates to one person every minute (1). These figures alone have an important impact on regional and national health systems. Compounding this important public health issue with the free movement of professional across countries, there is a need to establish some form of harmonisation in the definition of respiratory medicine, training and education of health professionals, and ultimately in the treatment and care of patients. As outlined by the European Lung White Book, in contrast to other medical specialities, respiratory medicine has several synonyms, with physicians known as respiratory physicians, pneumologists, pulmonologists, respirologists, lung doctors, chest physicians or thoracic physicians (2).

The European Respiratory Society (ERS) is an international membership organisation that brings together physicians, healthcare professionals, scientists and other experts working in respiratory medicine. ERS' mission is to promote lung health in order to alleviate suffering from disease and drive standards for respiratory medicine globally.

In 2005, the ERS curriculum design methodology, formerly known as 'HERMES' (harmonised education and training in respiratory medicine for European specialists) was launched with the goal to harmonise education and training and to address the heterogeneity of respiratory health training across Europe (3). Since then, various educational activities have been developed for different target audiences. Moving forward, ERS strives to provide a structure for the continuing professional development of respiratory physicians.

\section{Aim \& methodology}

The aim of the HERMES initiative was to achieve 


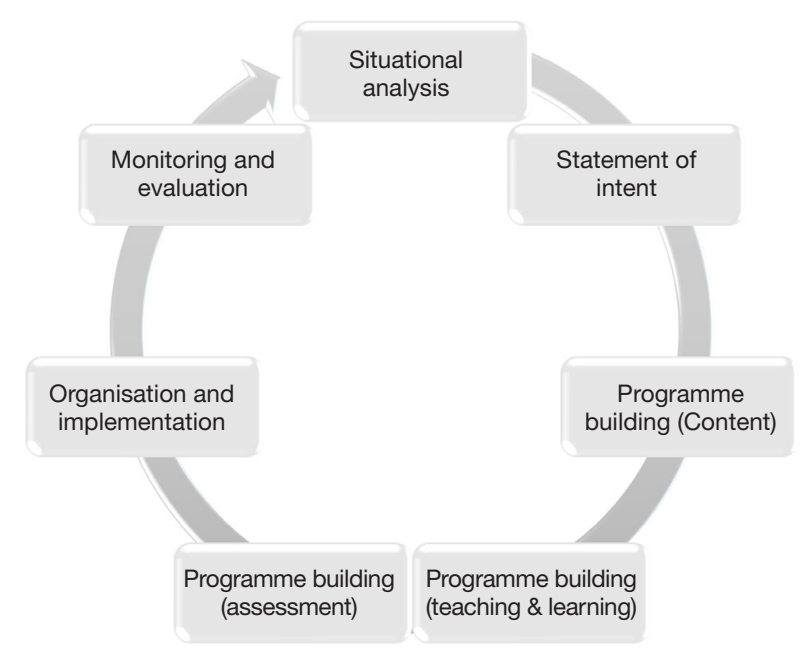

Figure 1 The situational model (7).

standardisation of training across Europe by setting the standards for all aspects of training, free movement of trainees across centres and nations, as well as the delivery of the best care to patients with respiratory diseases.

To reach this aim, processes and methodology were required to be put in place. A benchmark analysis was performed to determine what has been attempted in other medical fields. It was found that the initial step towards harmonisation of education and training throughout Europe was to develop core, consensus-based documents (4).

Different consensus group methods, such as the nominal group technique and the Delphi technique, were examined for best fit for the purpose of the project, which was syllabus and curriculum development. These methods aim to define "how well experts agree on a particular issue" and rely on the idea that best results can be obtained "by consulting a panel of experts and accepting group consensus" (5). The Delphi technique was chosen and adjusted to meet the project needs. (For more information, the modified Delphi technique used for ERS projects is extensively described in the "Methodology of curriculum development" of this issue).

Any curriculum development involves consideration of educational strategies, course content, learning outcomes, educational experiences and assessments, educational environments, learning styles, personal timetables and programmes of work (6). The Prideaux model (7) (Figure 1) has been used to structure each of the steps to be taken in order to develop an effective curriculum. This model places particular emphasis on the importance of context. As an international initiative this overview ensures that the curriculum developed is both applicable and acceptable across countries.

\section{Projects history}

\section{Adult respiratory medicine (ARM)}

With a focus on ARM for trainees, the first project was successfully developed:

(I) A core syllabus describing the essential topics any physician should possess to become a respiratory specialist (4);

(II) Curriculum recommendations suggesting how competencies should be taught and learned (8);

(III) A voluntary European examination to assess whether specialists have acquired the knowledgebased component of competence (9);

(IV) A summer school to cover the major fields of the curriculum and to prepare for the examination (10);

(V) An accreditation methodology for training centres $(11,12)$.

To reflect the developments in the field since 2006, the ARM syllabus was updated in 2018 (13). Before publication, the national Societies were asked to compare this new syllabus with that of their country (if any). Results showed that the syllabi of Portugal, the Netherlands, Estonia, United Kingdom, Germany and Bulgaria had greater than $90 \%$ similarity with the new European version. Moreover, this updated syllabus is the starting point for the Continuing Professional Development project, which has the objective to develop a framework for respiratory physicians to remain up-to-date in clinical practice.

Based on the syllabus, the ERS HERMES examination in ARM was developed in 2008. The examination is a knowledge-based, written assessment, comprising 90 multiple-choice questions, mainly with clinical vignettes, to test applied knowledge. The exam is recognized as part of a national, final exit examination in respiratory medicine in growing number of countries (for instance Switzerland) but can also be used by candidates for benchmarking against international standards. All respiratory specialists passing the examination receive the well-recognised HERMES European Diploma.

The self-assessment course launched in 2017 is similarly gaining recognition across Europe. This 1-hour mock examination of 30 multiple-choice questions selected from the HERMES exam question pool is followed by a 2-hour interactive discussion with an ERS expert. This formative 
assessment is designed as a quick educational and selfassessment tool for respiratory specialists and trainees.

The criteria for the accreditation of ERS European training centres in ARM were defined in 2010. The accreditation programme for training centres was then launched in 2014 in partnership with the European Board for Accreditation in Pneumology (EBAP). The process is voluntary and is broken down into two steps: firstly, qualification and secondly, a site visit.

\section{Paediatric respiratory medicine (PRM)}

Following the success of the first project in ARM, the ERS Paediatric Assembly endeavoured to update the existing PRM syllabus, which was developed in 2002 (14) and to harmonise standards by creating:

(I) A European curriculum, built on the updated syllabus (15);

(II) A European examination in PRM (16);

(III) A summer school to cover the major fields of the curriculum and to prepare for the examination (17), and;

(IV) Training networks and training centre accreditation (18).

The same methodology as the ARM project was applied in developing consensus documents. Firstly, the syllabus was reviewed and published in 2009. This publication and the curriculum rationale for ARM provided the basis for the curriculum development in PRM. Contemporaneously, initial steps were taken to develop the HERMES examination in PRM, which was launched at ERS Congress in Amsterdam 2011, and criteria for training centre accreditation, which were published in 2016.

The ERS HERMES examinations are receiving acclaim not only in Europe, but increasingly also outside of Europe. The HERMES examination in PRM is being successfully delivered in Asia, and new possible exam deliveries are being planned.

Moreover, the syllabus published in 2009 is currently under review to reflect the last developments in the field.

\section{Spirometry training programme}

The framework was subsequently used to develop a training programme for spirometry. The target audience for this programme is all healthcare professionals who require a comprehensive understanding and the basic skills in spirometry practice, which includes all professionals from doctors in primary care to specialists in a hospital setting (19). The programme aims to "to train and qualify health professionals to perform high-quality spirometry tests as well as increasing the number of accurate and repeatable spirometry measurements to be used in the diagnosis of patients with respiratory symptoms" (20).

The content of the training programme was designed following the methodology of previous projects and is now divided into two parts:

(I) Knowledge and basic skills;

(II) Knowledge and competence in measurement.

A third part focused on interpretation of spirometry results has been developed and implemented within the annual ERS international congress.

\section{Respiratory critical care}

The objectives of the project were to provide educational standards, a training framework in respiratory critical care medicine and to define the level of competence for adult respiratory physicians. The definition of Respiratory critical care was the first challenge of this project as it is not a speciality of its own and its training differs significantly across countries (21). The curriculum defines specific competencies and provides a usable framework in the training of clinicians in respiratory critical care (22).

\section{Respiratory sleep medicine}

The ERS organised postgraduate courses in respiratory sleep medicine and realised that expectations and requirements for structured training were not being met with a single educational intervention (23). The respiratory sleep medicine curriculum was developed to support teaching and certification in respiratory sleep medicine and to create a common standard for usage in daily practice.

A training programme has been developed based on the curriculum and aims at training respiratory professionals at a post-speciality level in respiratory sleep medicine. This two-part programme guides learners through the knowledge and skills required to obtain ERS certification in the main respiratory sleep topics (24).

\section{Thoracic oncology}

The thoracic oncology project was started as consensusbased documents were needed in this interdisciplinary field, where no harmonised structured training was defined. The aim was to give a comprehensive review of the current 
status of thoracic oncology training and to examine how to raise thoracic oncology skill levels (25). The target audience of this curriculum is respiratory physicians, medical oncologists, radiation oncologists and thoracic surgeons.

\section{Respiratory physiotherapy}

This project was launched to address the heterogeneity of respiratory physiotherapy education in Europe. The curriculum describes the core set of knowledge, skills, attitudes and competencies that physiotherapists require to assess, treat and follow patients with respiratory disorders (26) and is planned for publication beginning 2019.

\section{Respiratory infections}

As most countries do not have their own system for training physicians in respiratory infections, ERS took the lead to fulfil this unmet need (27). The syllabus outlining the essential topics that qualified respiratory physicians with a special interest in respiratory infections should know has been published in December 2018 (28).

\section{Thoracic surgery}

Given the disparity of training in thoracic surgery across countries and the lack of consensual definitions of prerequisites for the UEMS/European Board of Thoracic Surgery examination, there was an obvious need for a curriculum in this field (29). ERS and the European Society of Thoracic Surgeons (ESTS) cooperated to develop a harmonized European training syllabus for thoracic surgery and are currently finalising the curriculum.

\section{Endobronchial ultrasound (EBUS)}

The objectives of this project were to investigate, formulate and implement a comprehensive training programme to train qualified respiratory specialists to be able to competently perform EBUS. The target audience was defined as qualified medical doctors with previous experience in: performing bronchoscopies; TNM (tumour, node, metastasis) classification of lung cancer; and staging of oncology patients and other conditions (30). The programme is in three parts and will ensure that participants have all the necessary knowledge and skills required to obtain ERS certification in EBUS (31).

\section{Continuing professional development project}

ERS has overs 36,000 respiratory professional and scientist members representing over 160 countries worldwide. The society aims to address the requirements of a world-wide audience and recognises the heterogeneity of their contexts and wishes. Aiming to generate the greatest effectiveness in providing medical education and to tailor the activities to the preferences of the target population, ERS is now developing a structure for clinicians in respiratory medicine for Continuing Professional Development, the CPD programme.

Eight major diseases areas have been defined (shown in Figure 2): airway diseases, respiratory infections, interstitial lung diseases, pulmonary vascular diseases, respiratory critical care, respiratory sleep and breathing disorders, thoracic oncology and paediatric respiratory diseases.

Seven focus groups identified topics from the ARM syllabus, in which respiratory physicians involved in patient care should keep up-to-date. For each identified subject, top level topics were described. One focus group identified topics from the PRM syllabus, in which general paediatricians with an interest in PRM should keep up-to-date. The syllabi and curricula previously produced have been used as a basis for selection of relevant topics for specialists. The techniques, such as EBUS, spirometry or the upcoming Thoracic Ultrasound training programmes are transversal to the eight disease areas. A key focus area in 2019 will be on cystic fibrosis (CF). With the improved survival rates, an increasing number of patients are reaching adulthood. ERS is looking at developing a multidisciplinary working group to consider the educational needs of CF health professionals, including important topics such as: the complexity of the disease, the psychological burden on patients and their families, organ transplantation and end of life management (32).

\section{Perspective}

The ultimate aim of ERS CPD programme is to provide guidance for members involved in patients care in advising topics required to be "up-to-date" in each of the eight respiratory disease areas. Equally important, the CPD programme facilitates structuring of existing activities by assuring coverage completeness over medium-term cycles and establishment of links between disease areas. 

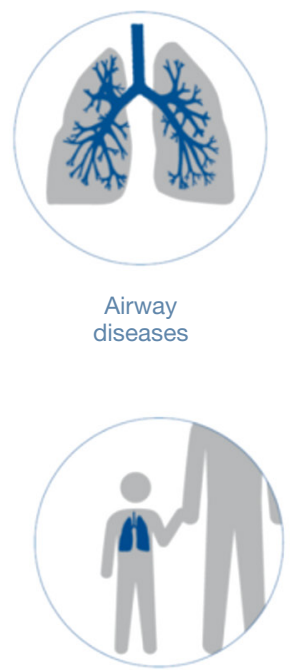

Paediatric respiratory diseases
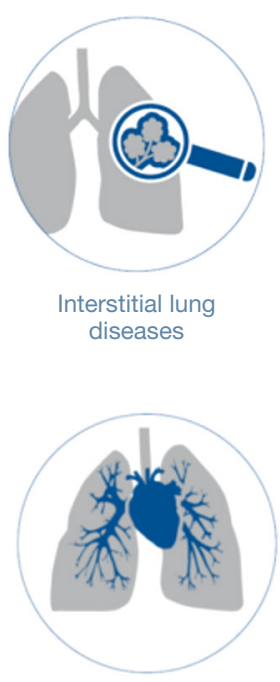

Pulmonary vascular diseases

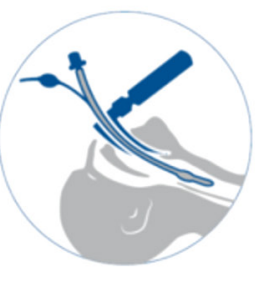

Respiratory critical care

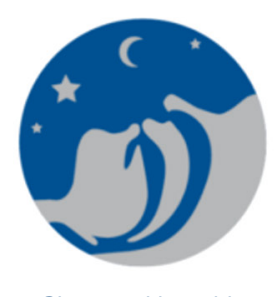

Sleep and breathing disorders

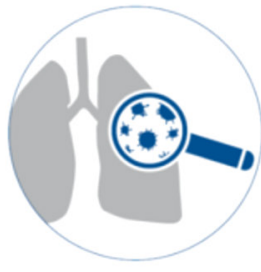

Respiratory infections

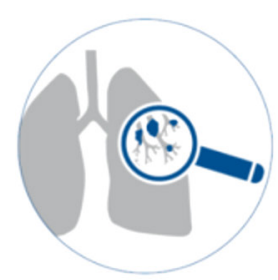

Thoracic oncology

Figure 2 The eight major disease areas.

\section{Acknowledgments}

Funding: None.

\section{Footnote}

Provenance and Peer Review: This article was commissioned by the Guest Editor (Gilbert Massard) for the series "Training in Pulmonary Medicine and Surgery" published in Fournal of Thoracic Disease. The article has undergone external peer review.

Conflicts of Interest: All authors have completed the ICMJE uniform disclosure form (available at http://dx.doi. org/10.21037/jtd.2019.02.40). The series "Training in Pulmonary Medicine and Surgery" was commissioned by the editorial office without any funding or sponsorship. DS: Grants from Astra-Zeneca AG, Curetis AG, Boston Scientific; Payment for lectures including service on speakers bureaus from Astra-Zeneca AG, Novartis AG, GSK AG, Roche AG, Zambon, Pfizer and Schwabe Pharma AG, Vifor AG. NT reports being an Employee of European Respiratory Society. AF reports being an Employee of European Respiratory Society. The authors have no other conflicts of interest to declare.

Ethical Statement: The authors are accountable for all aspects of the work in ensuring that questions related

to the accuracy or integrity of any part of the work are appropriately investigated and resolved.

Open Access Statement: This is an Open Access article distributed in accordance with the Creative Commons Attribution-NonCommercial-NoDerivs 4.0 International License (CC BY-NC-ND 4.0), which permits the noncommercial replication and distribution of the article with the strict proviso that no changes or edits are made and the original work is properly cited (including links to both the formal publication through the relevant DOI and the license). See: https://creativecommons.org/licenses/by-nc-nd/4.0/.

\section{References}

1. The burden of lung disease. Available online: https://www. erswhitebook.org/chapters/the-burden-of-lung-disease/

2. Available online: https://www.erswhitebook.org/chapters/ editors-introduction/

3. ERS curriculum design: a summary of projects. Available online: https://www.ersnet.org/professional-development/ ers-curriculum-design-a-summary-of-projects

4. Loddenkemper R, Séverin T, Eiselé JL, et al. HERMES: a European Core Syllabus in Respiratory Medicine. Breathe 2006;3:59-69.

5. Humphrey-Murto S, Varpio L, Gonsalves C, et al. Using consensus group methods such as Delphi and Nominal Group 
in medical education research. Med Teach 2017;39:14-9.

6. Harden RM. AMEE Guide No. 21: Curriculum mapping: a tool for transparent and authentic teaching and learning. Med Teach 2001;23:123-37.

7. Prideaux D. ABC of learning and teaching in medicine. Curriculum design. BMJ 2003;326:268-70.

8. Loddenkemper R, Haslam PL, Séverin T, et al. European Curriculum Recommendations for Training in Adult Respiratory Medicine. Breathe 2008;5:80-93.

9. Noël JL, Séverin T, Bloch KE. The European Diploma in Adult Respiratory Medicine: a label of quality for adult respiratory medical specialists. Breathe 2010;6:191-4.

10. Summer schools of adult and paediatric respiratory medicine: course report. Available online: http://breathe. ersjournals.com/content/14/1/9

11. Loddenkemper R, Séverin T, Mitchell S, et al. Adult HERMES: criteria for accreditation of ERS European training centres in adult respiratory medicine. Breathe 2010;7:170-88.

12. Sutter S, Stolz D, Karg O, et al. HERMES European Accreditation of Training Centres in Adult Respiratory Medicine: criteria validation and revision. Breathe 2016;12:11-7.

13. Tabin N, Mitchell S, O'Connell E, et al. Update of the ERS international Adult Respiratory Medicine syllabus for postgraduate training. Breathe 2018;14:19-28.

14. Zach MS; Long Range Planning Committee, Paediatric Assembly of the European Respiratory Society, Committee on Paediatric Respiratory Training in Europe, European Board of Paediatrics. Paediatric respiratory training in Europe: syllabus and centres. Eur Respir J 2002;20:1587-93.

15. Gappa M, Noël JL, Séverin T, et al. Paediatric HERMES: a European Syllabus in Paediatric Respiratory Medicine. Breathe 2009;5;236-47.

16. Mitchell S. HERMES examinations in adult and paediatric respiratory medicine. Breathe 2011;7;311-2.

17. Summer school of paediatric respiratory medicine. Available online: https://www.ersnet.org/professionaldevelopment/courses/summer-school-of-paediatricrespiratory-medicine-2019

18. Sutter S, Mitchell S, Eber E, et al. Paediatric HERMES: European accreditation of training centres in paediatric respiratory medicine. Breathe 2016,12;105-10.

19. Spirometry Training Programme. Available online: https:// www.ersnet.org/professional-development/spirometrytraining-programme

20. Cooper BG, Steenbruggen I, Mitchell S, et al. HERMES Spirometry: the European Spirometry Driving Licence.
Breathe 2011;7:258-75.

21. Respiratory critical care HERMES: a European core syllabus in respiratory critical care medicine. Available online: http://breathe.ersjournals.com/content/8/3/216

22. Respiratory Critical Care HERMES: European curriculum recommendations. Available online: http://breathe. ersjournals.com/content/10/1/15

23. Sleep HERMES: a European Core Syllabus in respiratory disorders during sleep. Available online: http://breathe. ersjournals.com/content/8/1/61

24. Respiratory Sleep Certified Training Programme. Available online: https://www.ersnet.org/professional-development/ respiratory-sleep-certified-training-programme

25. Meert AP, Noël JL, Boffetta P, et al. Thoracic Oncology HERMES: a European syllabus towards a harmonised education and training of Thoracic Oncology specialists. Breathe 2013;9:381-92.

26. Development of a syllabus for postgraduate respiratory physiotherapy education: the Respiratory Physiotherapy HERMES project. Available online: http://erj.ersjournals. com/content/45/5/1221

27. Introducing a new HERMES project on respiratory infections. Available online: http://breathe.ersjournals. com/content/12/1/5

28. ERS syllabus for postgraduate training in respiratory infections: a guide for comprehensive training. Available online: https://breathe.ersjournals.com/content/14/4/269

29. A harmonised European training syllabus for thoracic surgery: report from the ESTS/ERS task force group. Available online: http://erj.ersjournals.com/content/51/6/1 800370 ? ctkey=shareline

30. Endobronchial ultrasound: launch of an ERS structured training programme. Available online: http://breathe. ersjournals.com/content/12/3/217

31. Endobronchial Ultrasound (EBUS) Certified Training Programme. Available online: https://www.ersnet.org/ professional-development/endobronchial-ultrasoundcertified-training-programme

32. Elborn JS, Bell SC, Madge SL, et al. Report of the European Respiratory Society/European Cystic Fibrosis Society task force on the care of adults with cystic fibrosis. Eur Respir J 2016;47:420-8.

Cite this article as: Stolz D, Tabin N, Farr A. Harmonisation of respiratory medicine: the success story of European curriculum development. J Thorac Dis 2021;13(3):2029-2034. doi: $10.21037 /$ jtd.2019.02.40 